\title{
Images Of Online Versus Store Shopping: Have The Attitudes Of Men And Women, Young And Old Really Changed?
}

Kirsten A. Passyn, Salisbury University, USA Memo Diriker, Salisbury University, USA

Robert B. Settle, Salisbury University, USA

\begin{abstract}
This study examines the effect of the consumers' sex and age on their perceptions of the problems and the benefits of shopping and buying online, compared to doing so in a traditional retail store. Overall image profiles can be viewed, but the principal focus is on the similarities and differences between gender and age groups. Along with perceptions of problems and benefits of online buying, a direct comparison between store versus online buying sharply reveals the contrasts among men and women of different ages.
\end{abstract}

Keywords: Consumer Behavior; Database Marketing; Direct Marketing; Electronic Commerce; Online Shopping; Gender Effects

\section{INTRODUCTION}

\section{Adoption by Consumers}

iven the degree of effort required of the public who use the Web, the acceptance and adoption of this innovation has been extremely swift. However, many initial concerns, especially in terms of online shopping, remain. We propose that unlike users of MP3 players, such as the iPod, who play a passive role while listening or watching, users of the Internet must initiate the connection, specify the location to be visited, and largely control the interaction from beginning to end. For example, when downloading music on iTunes the passive listener described above must become an active participant. With such demands on the user, some demographic groups might be expected to approach adoption of online shopping very differently, with different concerns, and at a different pace than others.

Research shows that there seems to be an identifiable segment of consumers that has a preference for the Internet as a retail shopping alternative. (Keen, Wetzels, Ruyter, \& Feinberg, 2004) As of November 2008, 73\% of American adults were Internet users but only $40 \%$ of American adults were consider regular Internet users. Consumers' attitudes and behavior toward online shopping are influenced by many factors such as ease of use, usefulness, enjoyment, and risk. However, even with its ease of use, the risks inherent in online shopping, specifically the interaction between product risk and e-tail format, remain major concerns and reasons for consumers' hesitation to buying online. (Liu, 2004; Zhou, Dai, \& Zhang, 2007)

\section{Adoption by Marketers}

While there are myriad uses for the Internet that are important and valuable, use of the Web as a commercial vehicle has far outstripped all other functions, combined. The Internet as a marketing tool has facilitated significant changes in business marketing, such as productivity improvements, new business models, and increased focus on customer services. (Stevens, 2000; Tiago, Borges, Couto, Natário, \& Braga, 2007) In addition to direct 
online shopping, consumers are using the Internet to research products that they buy offline. Direct marketers, as well as many traditional store owners, were quick to see the possibilities, and in fact, the necessity for a substantial presence on the Web. (Stanley, 2000)

In the beginning, there were many predictions regarding what could and could not be marketed successfully on the Web. Some said only a narrow range of goods could be sold online. (Essick, 1997) This research detailed the limitations of online shopping including concerns about privacy, shipping, and the lack of shopping experience. Others took the opposite view, assuming almost anything could be marketed online with success if only the right methods were used. (Spinale, 1999) This research detailed the benefits of online shopping including convenience, selection, and price comparison. Most took the middle ground, though nobody seemed to doubt, almost from the very beginning, that online marketing was here to stay and would find a substantial share of a wide variety of both consumer and commercial markets as the technology developed. (Alba, Lynch, Weitz, Janiszewski, \& et al., 1997)

\section{Competitive Pressures}

The increasingly popular online shopping activity has resulted in significant online retail sales which are estimated to grow even bigger from $\$ 156$ billion in 2009 to $\$ 240$ billion in 2012. (Leggatt, 2010) Retail Internet sales have been growing at a strong and steady pace in recent years, so much so that annual growth for many online merchants has been in the double digits. (McIntosh, 2003) But the online marketing inroads into store marketing sales volume may be limited. Recent research shows that retail stores are still preferred over catalogs and the Internet due to stores' retail format. (Keen, et al., 2004) Store merchandisers may also strive to match or even exceed the selection and economy offered online. Furthermore, in recent years the majority of all major retailers have become multi-channel, offering access to consumers through their stores, catalogs, and Websites. (Deighton, 1997) In fact, the expansion of stores such as Best Buy, Walmart, and Barnes and Noble from "bricks and mortar" to "clicks and mortar" is considered a strategic necessity (Bernstein, Song, \& Zheng, 2008) The growth of outlets such as warehouse/membership clubs, big box retailers, category killers and superstores reflect these strategies. (Liebmann, 1998; O'Conner, 1999)

Competition from online marketers may also be a major concern of catalogers and other direct marketers. Many Internet retailers are now approaching revenues equal to that of catalog sales, and many online retailers are now enjoying profitability. (McIntosh, 2003) Most consumer catalogers have already established their presence on the Web. (Miller, 1998) Others, such as television direct marketers, including QVC and Home Shopping Network, have substantial investments in their Websites and online marketing operations. (Galenskas, 1997) Because of their extensive experience with direct, data based marketing, catalogers and other direct marketers are well positioned to move quickly and effectively to online consumer marketing. As such, they intensify the threat they already pose to traditional store merchandisers.

\section{Perceptions \& Comparisons}

The pictures in the mind's eye of consumers regarding online and store shopping and buying are likely to play an important role in encouraging or inhibiting adoption of online buying. (Korgaonkar, Silverblatt \& Girard, 2006) To what degree do visions of difficulty, confusion, or frustration inhibit adoption of online purchasing? And just how much do visions of ease of shopping or time savings encourage it? Do consumers continue to see in store shopping as entertaining and online shopping as boring? This research is designed to re-examine if these initial concerns over online shopping continue, and if these concerns vary by demographics.

\section{Ascribed Social Roles}

The two main ascribed social roles-those associated with one's age and sex-have a profound effect on virtually every aspect of human behavior, including the purchase and consumption of goods and services. This includes both how goods and services are purchased and what outlets are patronized.

Even though they are often simultaneously both homemakers and employed outside the home, women continue to make the vast majority of family purchases. (Alavi, 2009) Shopping and buying for the family remains 
almost exclusively the province of women. Research indicates shopping and buying are more pleasurable, or at least less unpleasant activities to women than to men. (Alreck \& Settle, 2002) Consequently it is important to examine gender differences between store versus online shopping perceptions.

Despite women's significant role on household purchases, shopping behavior for the male population is increasingly noticeable. Evidently, millions of boomer dads are shopping more than their fathers or grandfathers. In terms of online shopping men have been earlier adoptores and users of e-tailing than women. (Van Slyke, Comunale, \& Belange, 2002) Specifically, younger males and teenagers are more proficient with Web research skills which give them advantage in online shopping. (Byrnes, 2006) Moreover, in terms of online shopping, research shows that men are more likely to make purchases and spend more money online due to its convenience and reduced social interaction. (Stafford, Turan, \& Raisinghani, 2004) In contrast, women remain reluctant to give up the conventional shopping experience with its sensory, emotional, and aesthetic experience. (Klerk \& Lubbe, 2008)

Just as sex roles dictate that one should "be a man" or "act like a lady," so, too, do ascribed age role prescriptions indicate how one should "act your age." Such age role prescriptions, together with the differences in the maturation, history and situation of different age cohorts can be expected to exert a measurable influence on the adoption of a technological innovation as dramatic and far-reaching as the Internet and Web.

\section{Research Focus}

This study is designed to review the sex and age effects on consumer perceptions of the problems and benefits associated with online shopping and buying. Specifically although overall image profiles are discernable, the main focus is on the similarities and differences between sex and age groups. Have differences among these groups mitigated initial online shopping concerns?

\section{METHODOLOGY}

A survey of 1,060 adult consumers residing in the Mid-Atlantic region of the United States was conducted, in 2009. The questionnaires were delivered and retrieved by university student field workers who were assigned a quota, based on the age and sex of the respondents. Respondents were required to have access to a computer at home, connection to the Internet, and at least some online experience on the World Wide Web to qualify for participation.

\section{Online Shopping Problems and Benefits}

The survey questionnaire included 15 statements regarding potential online buying problems and 15 describing potential benefits. These items were gleaned from a literature review and confirmed through focus group discussions among those with online shopping experience. To indicate their opinions, respondents checked a box on a 5-point scale with extremes labeled "No Problem" and "Major Problem" or "No Benefit" and "Major Benefit," respectively.

\section{Online Versus Store Comparisons}

The survey also included a direct comparison between store shopping and online shopping experiences. Again these survey questions were gleaned from a literature review and confirmed through focus group discussions. There were 8 positive and 7 negative statements. Respondents recorded their ratings on 7-point comparative scales. They were instructed to check one box on each line to show their opinion of online shopping compared to shopping in a store. The extremes of the scale were labeled "Less Than a Store" and "More Than a Store" while the midpoint was labeled "Same as a Store." 


\section{Demographic Status}

Respondents indicated their sex, age, marital status, education level, employment category, occupational category, home ownership, and family income in the demographic section of the questionnaire. These data measured field worker adherence to quota specifications, as well as indicating the nature of the population represented.

\begin{tabular}{|c|c|c|c|}
\hline \multicolumn{4}{|c|}{$\begin{array}{c}\text { Table 1 } \\
\text { Demographic Distributions of the Sample }\end{array}$} \\
\hline \multicolumn{2}{|c|}{ Percent } & \multirow{2}{*}{$\begin{array}{l}\text { Occupation } \\
\text { Professional- }\end{array}$} & \multirow{2}{*}{$\begin{array}{r}\text { Percent } \\
15.0\end{array}$} \\
\hline $\operatorname{Sex}$ & & & \\
\hline Male------------------------------ & 50.0 & Executive, Managerial ---------- & 14.7 \\
\hline Female --------------------------- & 50.0 & Engineering, Technical -------- & 5.0 \\
\hline Age & & Administrative, Clerical --------- & 12.0 \\
\hline Under 35 -----. & 34.1 & Sales, Marketing -- & 14.0 \\
\hline 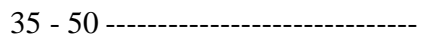 & 32.5 & Skilled, Semi-skilled ----------. & 10.0 \\
\hline Over 50 - & 33.4 & Not Employed --------------- & 29.3 \\
\hline Marital Status & & Home Ownership & \\
\hline Married -------- & 61.0 & Owner -----------. & 73.1 \\
\hline Not Married------------. & 39.0 & Renter ---------------------------- & 26.9 \\
\hline Education & & Family Income & \\
\hline High School Only ------------ & 26.9 & Under $20 \mathrm{~K}$ & 6.4 \\
\hline Some College---------- & 25.1 & 20K TO $39 \mathrm{~K}--$ & 9.2 \\
\hline 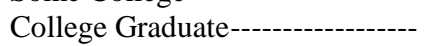 & 34.2 & 40K TO 59K-------- & 12.4 \\
\hline Post-Graduate----------------- & 13.9 & 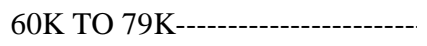 & 11.4 \\
\hline Employment & & 80K TO 99K-- & 6.8 \\
\hline Company Employed ------------ & 46.7 & 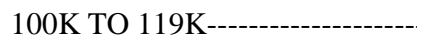 & 10.0 \\
\hline Education or Government-------- & 16.4 & 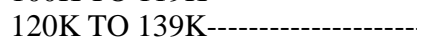 & 5.3 \\
\hline Self-Employed------------------ & 13.2 & 140K \& OVER & 7.3 \\
\hline Not Employed -- & 23.8 & Refused----------------------------- & 31.3 \\
\hline
\end{tabular}

Total $\mathrm{N}=1,060$

\section{RESULTS}

\section{Sample Demographics}

Table 1 displays the demographic distributions of response for the entire sample. The similarities of proportions of respondents of each sex reflect the sample quota specifications. The convenience sample of respondents tended to be more educated, affluent, and engaged in more up-scale occupations than the general population from which it was drawn.

\section{Rating of Problems by Sex}

The mean ratings by men and women of potential problems regarding online shopping are depicted in Table 2. The items are listed in order from the most to least serious in the eyes of respondents. The two items rated as the most serious problems were both related to privacy: Sale of mailing lists and lack of security for card information. This indicates that although online retailers are aware of this concern their efforts have not erased consumer worries. Other items rated fairly high include too many banners and pop-ups and the possibility of receiving unwanted "spam" e-mail solicitations as the result of purchase. Again illustrating consumers continued privacy concerns. Another significant concern of consumers remains the inability to handle goods. The lack of tangibility especially in soft goods remains a barrier to internet shopping. Those seen as least vexing were about online shopping being a boring activity in which family and friends could not easily participate.

Six of the 15 items proved to differ significantly between men and women at the .05 level of probability. Women rated 5 of the 6 significant items as more important problems than did their male counterparts. These five items are the inability to handle goods, the cost of shipping, slow downloads, slow search, and boring. Combined we 
can assume that these complaints are associated with the lack of shopping experience online. The one exception, resulting in a statistically significant higher rating of the problem by men than women, dealt with the necessity to wait for delivery of online purchases. Again this suggests that women are engaged in the shopping experience more so than the purchase experience, while men are focused on the purchase and not the overall experience.

\begin{tabular}{|c|c|c|c|c|}
\hline \multicolumn{5}{|c|}{$\begin{array}{c}\text { Table } 2 \\
\text { Perceptions of Online Shopping Problems by Men and Women }\end{array}$} \\
\hline & Male & Female & Diff. & Prob. \\
\hline Sell mailing lists ---'-- & 4.1 & 4.1 & 0.1 & .428 \\
\hline Credit card insecure -------- & 3.8 & 4.0 & -0.1 & .063 \\
\hline Pop-ups, banners -------- & 3.7 & 3.8 & 0.0 & .570 \\
\hline Can't handle goods ----.. & 3.7 & 3.8 & -0.1 & .040 \\
\hline May get spam -------- & 3.6 & 3.7 & -0.1 & .108 \\
\hline Shipping costly** & 3.3 & 3.5 & -0.2 & .002 \\
\hline Sellers seek info --- & 3.3 & 3.2 & 0.1 & .346 \\
\hline Slow downloads $* *$ & 2.9 & 3.1 & -0.3 & .002 \\
\hline Descriptions sketchy -----. & 2.8 & 2.9 & -0.1 & .354 \\
\hline Buying records saved & 2.7 & 2.7 & 0.0 & 1.000 \\
\hline Ordering too slow ---------------- & 2.6 & 2.5 & 0.0 & .821 \\
\hline Delivery too slow* & 2.6 & 2.5 & 0.1 & .037 \\
\hline Search too slow** & 2.5 & 2.7 & -0.2 & .007 \\
\hline Boring, no fun** & 2.3 & 2.7 & -0.4 & .000 \\
\hline Lonely, no company -- & 2.1 & 2.2 & -0.1 & .199 \\
\hline
\end{tabular}

5-Point scale labeled 1 = "No Problem" and 5 = "Major Problem"

$*$ indicates significant at the .05 level

** indicates significant at the .01 level

\begin{tabular}{|c|c|c|c|c|}
\hline \multicolumn{5}{|c|}{$\begin{array}{c}\text { Table } 3 \\
\text { Perceptions of Online Shopping Benefits by Men and Women }\end{array}$} \\
\hline Benefit & Male & Female & Diff. & Prob. \\
\hline Shop anywhere--------------- & 4.3 & 4.3 & 0.0 & .472 \\
\hline Shop any time -- & 4.2 & 4.2 & -0.1 & .166 \\
\hline Can read ratings -------- & 3.6 & 3.5 & 0.0 & .558 \\
\hline Easier, less effort ------ & 3.7 & 3.5 & 0.1 & .067 \\
\hline Online is quicker* ${ }^{*--}$ & 3.7 & 3.5 & 0.2 & .019 \\
\hline 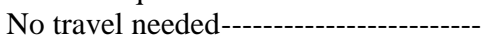 & 3.6 & 3.6 & 0.0 & .837 \\
\hline Easy price comparing*** & 3.6 & 3.4 & 0.2 & .001 \\
\hline More technical information -- & 3.4 & 3.3 & 0.1 & .105 \\
\hline Shop little at a time------------- & 3.4 & 3.4 & 0.0 & .502 \\
\hline Easier searching --- & 3.3 & 3.3 & 0.0 & .735 \\
\hline Good delivered*** & 3.0 & 3.4 & -0.4 & .000 \\
\hline Appearance irrelevant*** & 3.0 & 3.5 & -0.5 & .000 \\
\hline Greater selection*** & 3.3 & 3.1 & 0.3 & .000 \\
\hline 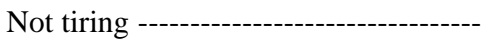 & 3.1 & 3.2 & -0.1 & .099 \\
\hline More interesting ---------------------- & 2.4 & 2.3 & 0.1 & .381 \\
\hline
\end{tabular}

5-Point scale labeled $1=$ "No Benefit" and $5=$ "Major Benefit"

$*$ indicates significant at the .05 level

** indicates significant at the .01 level

\section{Rating of Benefits by Sex}

Table 3 contains the mean ratings by men and women of the potential benefits of online shopping. These items were also sorted from the most to least beneficial in the eyes of respondents, rather than as they appeared in the questionnaire. The two items rated highest by far by both sexes related to being able to shop online any time, anywhere. By contrast, the potential benefit rated lowest suggests respondents rarely found online shopping more interesting or entertaining than store shopping. 
Just 5 of the 15 mean online benefit item ratings differed significantly between men and women, but 4 of the 5 were statistically significant at or beyond the .001 level of probability. Men rated the speed of online shopping and the ability to make price comparisons and wider selection offered as more important than women rated them. Women's mean ratings exceeded those of men on two benefits: Online purchases delivered and do not require the buyer to carry the goods home, and shopping can be done without regard for one's appearance. Again the benefits, as the problems, indicate a primary difference in shopping patterns between men and women. Women shop to shop while men shop to buy.

\section{Rating of Problems by Age Group}

The responding sample was divided into three groups: Under 35,35 to 50 , and over 50 years of age. The breakdown of mean ratings is shown in Table 4 . Six of the 15 problem items received significantly different mean ratings by age group. In every significant case, save one, the eldest group regarded the problem as more serious than did their juniors. The one exception was the item indicating that delivery of online purchases takes too long. In that case, the under 35 group rated it as most serious and the middle age group least serious, suggesting, perhaps, the purported impatience of youth. Overall these results indicate that older peoples' concerns of privacy and frustration with the online shopping experience prevail.

\begin{tabular}{|c|c|c|c|c|}
\hline \multicolumn{5}{|c|}{$\begin{array}{c}\text { Table } 4 \\
\text { Perceptions of Online Shopping Problems by Age Group }\end{array}$} \\
\hline Problem & $<35$ & $35-50$ & $>50$ & Prob. \\
\hline Sell mailing lists* & 4.0 & 4.2 & 4.2 & .041 \\
\hline Credit card insecure - & 3.9 & 3.9 & 4.0 & .184 \\
\hline Pop-ups, banners -- & 3.8 & 3.8 & 3.7 & .521 \\
\hline 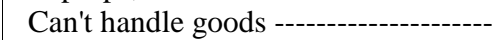 & 3.9 & 3.7 & 3.7 & .080 \\
\hline 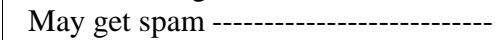 & 3.7 & 3.6 & 3.7 & .596 \\
\hline Shipping costly ----------- & 3.5 & 3.5 & 3.4 & .331 \\
\hline Sellers seek information** ${ }^{*}$ & 3.1 & 3.1 & 3.4 & .001 \\
\hline Slow downloads - & 2.9 & 3.1 & 3.1 & .080 \\
\hline Descriptions sketchy ----------------- & 2.8 & 2.8 & 2.9 & .506 \\
\hline Buying records saved ----------- & 2.6 & 2.6 & 2.9 & .006 \\
\hline Ordering too slow** & 2.4 & 2.5 & 2.8 & .000 \\
\hline Delivery too slow** & 2.7 & 2.4 & 2.6 & .010 \\
\hline Search too slow** & 2.4 & 2.6 & 2.9 & .000 \\
\hline 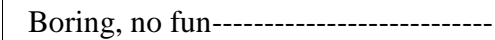 & 2.4 & 2.5 & 2.7 & .057 \\
\hline Lonely, no company ----------------- & 2.2 & 2.0 & 2.2 & .070 \\
\hline
\end{tabular}

\section{Rating of Benefits by Age Group}

Table 5 contains the mean ratings by age group of the potential benefits of online shopping. Of the 15 items, 8 resulted in statistically significant ratings by age. The four items dealing with the ability to shop online any time and anywhere, to read product ratings and comments, and to make price comparisons online were regarded as less important by the senior-most group, compared to the younger two groups. This indicates that younger consumers are using the internet as much for decision making as for purchasing. This distinction supports the need for both bricks and clicks for success. Freedom from the need for a means of transportation, from having to carry online purchases and the ability to shop without regard for personal appearance were least important for the under 35 group. The item stating that shopping online is more interesting or entertaining than store shopping received low ratings by all age groups, but the under 35 group provided significantly lower ratings than the other two age groups. This illustrates that the shopping experience is not well duplicated in the online environment. 


\begin{tabular}{|c|c|c|c|c|}
\hline \multicolumn{5}{|c|}{$\begin{array}{c}\text { Table } 5 \\
\text { Perceptions of Online Shopping Benefits by Age Group }\end{array}$} \\
\hline Benefit & $<35$ & $35-50$ & $>50$ & Prob. \\
\hline Shop anywhere ${ }^{* *}$ & 4.5 & 4.3 & 4.2 & .000 \\
\hline Shop any time** ${ }^{*}$ & 4.3 & 4.2 & 4.0 & .001 \\
\hline Can read ratings** & 3.7 & 3.6 & 3.4 & 016 \\
\hline Easier, less effort ----------- & 3.6 & 3.7 & 3.6 & .423 \\
\hline Online is quicker ---.-- & 3.6 & 3.7 & 3.6 & .222 \\
\hline No travel needed** & 3.4 & 3.7 & 3.6 & .010 \\
\hline Easy price comparing* & 3.6 & 3.5 & 3.4 & .012 \\
\hline 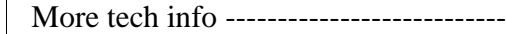 & 3.3 & 3.5 & 3.4 & .116 \\
\hline Shop little at a time-------. & 3.4 & 3.5 & 3.4 & .456 \\
\hline Easier searching -------------------- & 3.3 & 3.4 & 3.3 & .154 \\
\hline Good delivered**- & 2.9 & 3.3 & 3.4 & .000 \\
\hline Appearance irrelevant* & 3.1 & 3.4 & 3.3 & .043 \\
\hline Greater selection-- & 3.3 & 3.2 & 3.1 & .062 \\
\hline 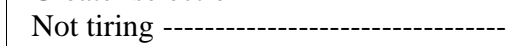 & 3.0 & 3.1 & 3.2 & .084 \\
\hline More interesting** & 2.2 & 2.5 & 2.4 & .001 \\
\hline
\end{tabular}

\section{Comparative Scale Ratings by Sex}

Figure 1 displays the mean ratings of online shopping compared to store shopping for men and women respondents. The two vectors - male versus female respondent ratings-differ significantly at the .001 level of probability.

For the entire responding sample, online shopping was seen as substantially time-saving, relaxing and easy in comparison with store shopping, but also slightly more confusing and boring. Online shopping was also considerably less tiring in the eyes of the whole responding sample, as well as somewhat less demanding, exciting, entertaining, stimulating, fun, and enjoyable. Both men and women viewed store and online shopping as almost equally difficult and frustrating.

Inspection of the dimensions on the lower portion of Figure 1; traits that both men and women felt were less typical of online shopping than store shopping reveal women's attachment to store shopping by comparison with men. Thus, they found online shopping to be markedly less enjoyable, fun, stimulating, entertaining, and exciting than did their male counterparts. By contrast, in comparison to store shopping, men found online shopping to be more relaxing and easier than did the women respondents. Taken as a whole, the results indicate men's comparisons of online and store shopping are markedly more favorable toward online channels, but it is uncertain whether this is because they like online shopping more than women or dislike store shopping more than women do.

\section{Comparative Scale Ratings by Age Group}

Figure 2 contains the graph of mean comparative scale ratings from those under 35,35 to 50 , and over 50 years of age. The differences among all three vectors proved to be significant at the .01 level of probability, however post hoc measures of differences between pairs of vectors revealed the vectors of ratings for the younger and older group did not differ significantly from one another, although both differed significantly from the middle-aged group. Thus, the results were somewhat more ambiguous than those for ratings by the two sexes.

Compared to store shopping, the mid-age group found online shopping to be more boring, time-saving, and enjoyable than their younger and older counterparts. Those in the younger group viewed online shopping to be less fun, tiring, frustrating, exciting, relaxing, and stimulating than store shopping to a greater degree than did the two senior groups. 

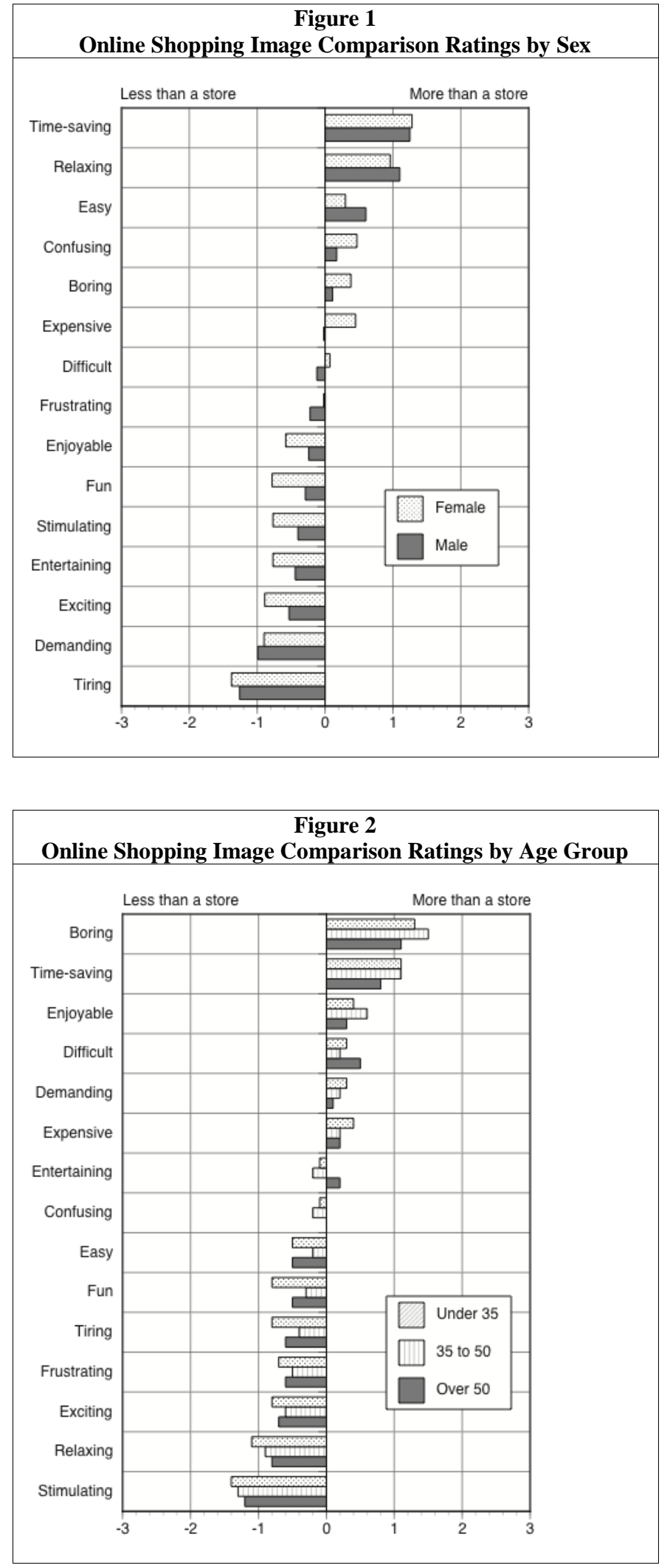


\section{CONCLUSIONS}

\section{Gender Effects on Reactions}

The differences between men and women in their responses to online shopping problems and concerns, to benefits and advantages, and among direct comparisons with store shopping were often statistically significant but never dramatically different. Yet there were some distinctions worth noting: Perhaps the most noteworthy difference between men's and women's ratings were for the statement, "Online shopping is more boring and less fun than store shopping." Women's enjoyment of store shopping is evident in their higher rating of that online shopping problem statement. Women were also more concerned than their male counterparts about the time and effort required to find what they want online. From a marketers point of view, and especially from an online marketers frame of reference, it would appear obvious that shopping online is quicker and easier than a trip to the store; however, this apparent contradiction is resolved if one finds store shopping to be fun and entertaining while that is not so for online shopping.

Differences between men's and women's reactions were also discernable in response to items about online shopping benefits and advantages. Men's ratings equaled or exceeded those of women for all but 3 of the 15 statements, but those three exceptions are noteworthy:

"Online purchases are delivered so I don't have to carry them."

"I can shop online without concern for my appearance."

"I can shop online as long as I want without getting tired."

Taken in conjunction with the ratings of shopping problems, the message from women seems to be that store shopping is more fun but online shopping is easier. By contrast, men appear to feel that online shopping is an effective way to avoid the hassle of store shopping.

When making direct comparisons between store and online shopping, on average, both sexes found online shopping to be less tiring, demanding, exciting, entertaining, stimulating, fun, and enjoyable; however, men saw store and online shopping to be more similar on all these dimensions than women did, except one: demanding. It should also be noted that on average, men viewed both shopping venues as about equally expensive, while women perceived online shopping as substantially more expensive than store shopping.

\section{Age Effects on Reactions}

The most senior group of respondents were more concerned than their juniors about problems of information security and about difficulty and complexity of online shopping. While the younger group was least concerned about sale of mailing lists. However, that and credit card information security were the two top concerns for all three age groups.

Among the items identifying potential online shopping benefits, the senior group's average ratings exceeded those of the others on only two items:

"Online purchases are delivered so I don't have to carry them."

"I can shop online without concern for my appearance."

The majority of items yielding the highest mean ratings were provided by those in the 35 to 50 age group. The topics of these items included online shopping being quick and easy, and a ready source of technical information. They also valued the ability to search for particular items online.

The direct comparisons between store and online shopping by the three age groups indicated that the younger group found online shopping to be less stimulating, relaxing, fun, and exciting, but also less tiring and frustrating than did their older counterparts. The three items where online shopping was rated most superior to store shopping were all rated higher by the 35 to 50 age group than by the older and younger group. The mid-age group found online shopping to be markedly more boring than did their juniors or seniors. 


\section{IMPLICATIONS}

\section{Privacy}

This study indicates that issues and concerns regarding information privacy and online security are paramount among both sexes and all ages. This was a major concern at the outset of online shopping and remains significant. This would indicate that although steps e-tailers have taken to ensure privacy have helped, they have not alleviated this major concern. It would therefore benefit online marketers to be especially eager to take whatever steps are necessary to make self-regulation and self-governance in the matter of privacy and security effective. Online and database marketers would be well advised to cooperate enthusiastically when regulation or legislation is proposed in order to avoid over-regulation and binding requirements and prohibitions.

Individual online marketers would benefit by adopting and promoting buyer-friendly online security, as well as confidence-building data collection and retention procedures. Such features as obscure opt-out options and verbose, fine-print statements of privacy policies, written largely in legalese, should be replaced by clear, open, easily understandable disclosure of the firm's or site's policies, practices, and security measures.

\section{Entertainment}

Consumers fall into two broad groups with regard to their attitudes toward store shopping: Some see it is as enjoyable, stimulating and sufficiently rewarding to be worth the effort. Others find it a chore, a drag, a hassle at best and something of a necessary evil. Online shopping is a natural alternative for the latter group, but a poor substitute for the former group. This distinction is predominately gender based. These results are confirmed elsewhere in the retail-only format, "Women are focused on the experience; men are on a mission" (Alavi 2009). That is women associate fun, excitement, entertainment, stimulation, and social companionship with a shopping trip; and therefore, online shopping may well be a poor substitute. Given that women account for $83 \%$ of consumer spending the challenge for online marketers is to increase the sensory stimulation and shopper participation without increasing the complexity or effort required of the consumer. To attain that, both advanced technology and great creativity will be required.

We forward several possibilities to this end. The younger generation is increasingly comfortable carrying out social relationships electronically, texting, twittering, facebooking, etc. Furthermore, this trend is rapidly growing in the more mature market. (Kirkpatrick, 2008) If e-tailers link to facebook or provide chat rooms to customers, women could benefit from the ease of online shopping while still receiving the pleasure and benefits of social interaction. One could imaging two women in different locations, late at night, perusing the same website and chatting occasionally, "ooh do you like this? Would this look good on me? What color do you prefer?"

Another critical component of the in store shopping experience according to Alavi (2009) is the interaction with sales associates, deemed experts in their product categories. In fact, the top problem according to women when in store shopping is "the lack of help when I needed it." Having sales associates available for immediate chat with customers is a relatively new yet still limited idea. We predict that this will soon become essential to capture the female market. Immediately available sales associates, knowledgeable with first hand experience, who can chat with online shoppers is as essential for e-tailers as it is for retailers. Furthermore, this inclusion of social dialogue to the online environment should improve its social and therefore entertainment value.

\section{Convenience}

The "anytime, anywhere" capability of online shopping was clearly appreciated by all respondents. It is highly unlikely that people will find more free time for shopping in the future. Probably the pressure on their time and demands for their attention will increase, rather than abate. As that happens, the convenience of online shopping and buying will become an ever more important factor, giving e-tailers an advantage especially if they can mitigate their disadvantages. 
Interestingly, men rated the benefits of speed, price comparison, selection, and marginally (.06) less effort as more valuable than women. This is in accord with what we know about men's retail shopping habits. Men treat shopping as more instrumental than women, with a "get it done efficiently" attitude. (Alavi 2009) This may imply that the very lack of social interaction and the efficiency of e-tailing is what attracts the male market. This would suggest that e-tailers need to be careful in how they apply the recommendations above. Chat links should not appear intrusive. That is you should have the option of opening the chat dialogue boxes. Furthermore, online sales associates, like in store sales associates need to be well trained in the differences between assisting men and women. Women want collaboration and opinion from their sales associates while men predominately want precise answers to precise questions.

\section{Online \& In Store}

Customers concerns with online retailing remain. All demographics remain concerned about privacy issues. And especially for women the in store appeal remains. In-store marketing is more entertaining and stimulating. Shoppers can handle and examine the goods in person before purchase. Overall these drawback of -e-tailing are more concerning to women than men. In contrast the benefits of online shopping are still that it is quick, easy, and extremely convenient. Furthermore, it is not very demanding and it readily enables search and comparison. Overall these benefits are more appealing to men than women. . Although we make suggestions to enhance the entertainment value of e-tailing and attract the social shopping female we doubt the ability of the internet to truly duplicate the shopping experience. However, given the ease and speed of online shopping and the continued time impoverished consumer, the necessity of both bricks and clicks seems obvious.

\section{REFERENCES}

1. Alavi, M. (2009) Men Buy, women shop: The sexes have different priorities when walking down the aisles. Knowledge@Emory, 12(17).

2. Alba, J., Lynch, J., Weitz, B., Janiszewski, C., \& et al. (1997). Interactive home shopping: Consumer, retailer, and manufacturer incentives to participate in electronic marketplaces. Journal of Marketing, 61(3), 38.

3. Alreck, P. L., \& Settle, R. B. (2002). Gender effects on Internet, catalogue and store shopping. Journal of Database Marketing, 9(2), 150.

4. $\quad$ Bernstein, F., Song, J., \& Zheng, X. (2008). Bricks-and-mortar" vs. "clicks-and-mortar": An equilibrium analysis. European Journal of Operational Research, 187(3).

5. $\quad$ Byrnes, N. (2006). Secrets Of The Male Shopper. Business Week(3999), 44.

6. Deighton, J. (1997). Commentary on "Exploring the Implications of the Internet for Consumer Marketing". Academy of Marketing Science. Journal, 25(4), 347.

7. Essick, K. (1997). Internet users slow to adopt electronic commerce. Computerworld, 31(15), 70.

8. $\quad$ Galenskas, S. M. (1997). Interactive shopping on the Internet. Direct Marketing, 60(4), 50.

9. Gude, J. (2008). Is your website pulling online buyers in to your store? Local Nation.

10. Keen, C., Wetzels, M., Ruyter, K. d., \& Feinberg, R. (2004). E-tailers versus retailers: Which factors determine consumer preferences. Journal of Business Research, 57(7), 685.

11. Kirckpatrick, D. (2008). Help wanted adults on Facebook. Fortune Magazine, 3(21) 11.

12. Klerk, H., \& Lubbe, S. (2008). Female consumers' evaluation of apparel quality: exploring the importance of aesthetics. Journal of Fashion Marketing and Management, 12(1).

13. Korgaonkar, P., Silverbalatt, P., \& Girard, T. (2006). Online retailing, product classifications, and Consumer Preferences. Journal of Internet Research, 16(3) 267.

14. Legatt H. (2010). U.S. online retail sales. Bizreport.

15. Liebmann, W. (1998). A little shop talk. Brandweek, 39(13), 25.

16. Liu, C. (2004). Modeling consumer adoption of the Internet as a shopping medium: An integrated perspective. Unpublished Doctoral, Auburn University, Auburn, Alabama.

17. McGaughey, R. E., \& Mason, K. H. (1998). The Internet as a marketing tool. Journal of Marketing Theory and Practice, 6(3), 1.

18. Miller, P. (1998). The vibes for 2001. Catalog Age, 15(7), 0_1. 
19. O'Conner, P. C. (1999). Which Retail Properties Are Getting Market Share? The Appraisal Journal, 67(1), $37-40$.

20. Settle, R. B., \& Alreck, P. L. (1989). Why They Buy: American Consumers Inside and Out. New York: John Wiley and Sons.

21. Spinale, L. (1999). CE giants chase Internet sales. Dealerscope Consumer Electronics Marketplace, 41(3), 12.

22. Stafford, T. F., Turan, A., \& Raisinghani, M. S. (2004). International and Cross-Cultural Influences on Online Shopping Behavior. Journal of Global Information Technology Management, 7(2), 70.

23. Stanley, J. (2000). New tools of the trade. Chain Store Age, 76(11), 102.

24. Stevens, R. P. (2000). The Internet changed business marketing--and it didn't. $B$ to $B, 85(16), 46$.

25. Tiago, M., Borges, T., Couto, J. P., Natário, M. M., \& Braga, A. (2007). International Reality of Internet Use as Marketing Tool. Journal of American Academy of Business, 11(1), 138.

26. Van Slyke, C., Comunale, C., \& Belange, F. (2002). Gener differences in perceptions of Web-based shopping. Association for Computing Machinery, 45(8).

27. Zhou, L., Dai, L., \& Zhang, D. (2007). Online Shopping Acceptance Model - a Critical Survey of Consumer Factors in Online Shopping. Journal of Electronic Commerce Research, 8(1), 41. 